ISSN 0103-6017

\title{
TEXTOS DE ECONOMIA
}

A Revista Textos de Economia é uma publicação semestral do Departamento de Ciências Econômicas da Universidade Federal de Santa Catarina que tem por objetivo oferecer um espaço à divulgação de artigos científicos de todas as filiações teóricas das ciências econômicas e das demais ciências sociais

\section{CONSELHO EDITORIAL}

Fernando Ferrari Filho - UFRGS

Francisco Paulo Cipolla - UFPR

Ivo Theis - FURB

José Gabriel Porcile Meirelles - UFPR

Ramon Vicente Garcia Fernandez - FGV-SP

Renato Kilpp - UFCG

Robert Wayne Samohyl - UFSC

Theotônio dos Santos - UFF

\section{COMITÊ EDITORIAL}

Helton Ricardo Ouriques

Patrícia F. F. Arienti

Roberto Meurer

Sílvio Cario

Editor Executivo

Helton Ricardo Ouriques

Bolsista

Sheyla Becker 
Alvaro Toubes Prata

Reitor

Ricardo José Araújo de Oliveira

Diretor Centro

Sócio-Econômico

Ivete Simionatto

Coordenador de Pesquisa do

Centro Sócio-Econômico

Helton Ricardo Ouriques

Chefe do Departamento de

Ciências Econômicas

Jaylson Jair da Silveira

Coordenador de Pesquisa do Depar-

tamento de Ciências Econômicas
COMISSÃO TÉCNICA

STUDIO S • Diagramação \& Arte Visual studios@studios.com.br (48) 3025-3070

Diagramação

Nova Letra Gráfica e Editora

Impressão

Lairton Marcelo Comerlatto

Revisão de Texto

Fernando Seabra e

Wagner Leal Arienti

Revisão de Texto em Inglês

Daurecy Camilo (Beto)

CRB - 14/416

Normalização

(Catalogação na fonte pela Biblioteca Universitária da Universidade Federal de Santa Catarina)

Textos de economia / Universidade Federal de Santa Catarina. Centro Sócioeconômico. Departamento de ciências econômicas. Curso de Mestrado em Economia. - v.1, n.1 (1986)- . -Florianópolis: PPGE : Departamento de Ciências Econômicas da UFSC , 1986 - v. ; 23 cm

Semestral

ISSN 0103-6017

1. Economia I. Universidade Federal de Santa Catarina. II.Departamento de Ciências Econômicas. III Curso de Mestrado em Economia

Tiragem: 500 exemplares

DIREITOS E PERMISSÃO DE UTILIZAÇÃO

Os artigos publicados são de total responsabilidade dos autores. É permitida a publicação de trechos e artigos com autorização prévia e identificação da fonte. 


\section{SUMÁRIO}

\section{ARTIGOS}

Notas sobre tecnologia e território no Brasil

Ivo Marcos Theis

$\mathrm{O}$ efeito transbordamento da crise econômica internacional Amarildo Hersen

Jandir Ferrera de Lima

Identificação e avaliação das ações institucionais e políticas públicas com foco nas demandas do Arranjo Produtivo Local (APL) de bonés de Apucarana no Estado do Paraná Antonio Carlos de Campos

Rafaella Stradiotto Vignandi 46

Diferenciais de salário entre trabalhadores qualificados e não-qualificados nas Regiões Metropolitanas de Campinas e de São Paulo

Bruna A. Branchi

Nelly Maria Sansigolo de Figueiredo

Leonardo Segura Moraes

Andrews Lima Silva Santos 
Efeitos redistributivos e determinantes de recebimento do ICMS

Ecológico pelos municípios mineiros

Luciany Lima Fernandes

Alexandre Bragança Coelho

Elaine Aparecida Fernandes

João Eustáquio de Lima ...................................................... 95 


\section{SUMMARY}

\section{ARTIGOS}

Notes on technology and territory in Brazil

Ivo Marcos Theis

The spillover effect of the international economic crisis Amarildo Hersen

Jandir Ferrera de Lima

Identification and evalution of the institutional actions and public policies with focus in local productive arrangement of hats and caps of Apucarana (Paraná)

Antonio Carlos de Campos

Rafaella Stradiotto Vignandi 46

Wage differentials between qualified and non-qualified workers in the metropolitan regions of Campinas and São Paulo Bruna A. Branchi Nelly Maria Sansigolo de Figueiredo Leonardo Segura Moraes Andrews Lima Silva Santos 
Redistributive effects and determinant of the ecological vat receivings by the cities of minas gerais - Brazil

Luciany Lima Fernandes

Alexandre Bragança Coelho

Elaine Aparecida Fernandes

João Eustáquio de Lima ....................................................... 95 


\section{APRESENTAÇÃo}

Apresentamos ao público leitor o primeiro número do Volume 13, da Revista Textos de Economia. A presente edição inicia-se com o artigo Notas sobre tecnologia e território no Brasil, de autoria de Ivo Marco Theis. Neste texto, o autor faz uma reflexão sobre a complexa relação entre desenvolvimento científico e tecnológico, desenvolvimento econômico e desenvolvimento social e sua expressão territorial. O segundo artigo, de autoria de Amarildo Hersen e Jandir Ferrera de Lima, O efeito transbordamento da crise econômica internacional, tenta mostrar a forma pela qual a crise econômica desencadeada em uma dada região atinge outras regiões. Para isso, os autores fazem um estudo de caso da crise econômica de 2008, nos Estados Unidos. O terceiro artigo da revista, de autoria de Antonio Carlos Campos e Rafaella Stradiotto Vignandi, Identificação e avaliação das ações institucionais e políticas públicas com foco nas demandas do arranjo produtivo local (APL) de bonés de Apucarana no Estado do Paraná, discute aspectos relevantes daquele Arranjo Produtivo, mostrando as demandas dos empresários do setor selecionado e identificando as ações institucionais e políticas públicas existentes. O quarto artigo, Diferenciais de salário entre trabalhadores qualificados e não-qualificados nas regiões metropolitanas de Campinas e de São Paulo, de Bruna A. Branchi, Nelly Maria Sansigolo de Figueiredo, Leonardo Segura Moraes e Andrews Lima Silva Santos, é um estudo empírico que objetiva avaliar os efeitos que abertura econômica teve no mercado de trabalho brasileiro, apresentando os resultados de pesquisa efetuada em duas regiões metropolitanas do Estado de São Paulo (Campinas e São Paulo, respectivamente). O quinto e último artigo da presente edição, intitulado Efeitos redistributivos e determinantes de recebimento do ICMS ecológico pelos municípios mineiros, escrito por Luciany Lima Fernandes, Alexandre Bragança Coelho, Elaine Aparecida Fernandes e João Eustáquio de Lima, faz uma análise da mudança na distribuição do ICMS nos muni- 
cípios de Minas Gerais com a introdução do critério ecológico, avaliando também os determinantes da probabilidade de os municípios pertencerem à categoria de receptores do ICMS ecológico.

Registramos, por fim, que a Revista Textos de Economia encontra-se disponível por meio eletrônico, na página de periódicos da Universidade Federal de Santa Catarina (www.periodicos.ufsc.br), através da qual pode ser feito todo o processo de submissão dos artigos e resenhas. Convidamos os leitores a acessarem a página e pesquisarem os números anteriores de nossa revista.

Boa pesquisa e boa leitura!

Helton Ricardo Ouriques

Editor da Revista Textos de Economia e Professor do CNM/CSE/UFSC 